\title{
Randomised trial of parental support for families with very preterm children
}

\author{
Avon Premature Infant Project
}

\begin{abstract}
Aim-To test the effectiveness of a home based developmental education programme in very preterm children. Methods-A randomised controlled trial was conducted of developmental or social support intervention, started at discharge for up to 2 years, in 309 consecutive survivors of 32 weeks gestation or less, born to mothers resident in greater Bristol between December 1990 and July 1993. Home visits were made by research nurses trained in either Portage (a developmental education programme) or in nondirectional counselling (parent adviser scheme). Interventions were also provided to appropriate primary care and community support for disability. Griffiths Mental Development Scales were used to assess outcome at 2 years.
\end{abstract}

Results-Mean (SEM) Griffiths quotients (GQ) were: Portage 96.8 (1.6); parent adviser 95.9 (1.6); preterm control 92.9 (2.0). Despite randomisation, social variables significantly confounded these results. Using linear regression analysis, intervention was associated with improved scores: Portage: +4.3 GQ points $(95 \%$ CI 1.6 to 7.0$)$; parent adviser: +3.4 GQ points (1.4 to 6.1). The effect of Portage was greatest in those children with birthweights $<1250 \mathrm{~g}(+5.3 \mathrm{GQ}$ points (0.2 to 10.4) and in those with an abnormal neonatal cerebral ultrasound scan $(+7.3$ GQ points (1.6 to 13.0 ).

Conclusion-Primary analysis showed no developmental benefit from long term family support after preterm birth. Secondary analysis controlling for the presence of adverse social markers showed similar small advantage for both intervention groups. In the smallest infants and those with brain injuries, a structured developmental programme may offer advantage over social support intervention. (Arch Dis Child Fetal Neonatal Ed 1998;79:F4-F11)

Keywords: home based developmental education programme; family support; developmental benefit

Children born very early or very small are at high risk of neurosensory impairments and disabilities. Such children have poorer scores on developmental and cognitive testing compared with their peers born at full term, even when children with major disabling conditions, such as cerebral palsy, are excluded. ${ }^{1}$ Suboptimal scores on tests of motor, cognitive, educational and behavioural function persist through to teenage years. ${ }^{23}$

The causes of this developmental disadvantage are uncertain but biological, social, environmental and psychological explanations have been proposed. Some disadvantage may be due to biological disturbances in brain development which are secondary to early delivery, specific perinatal insults, or aspects of postnatal care. Other disadvantage may relate to sociodemographic or environmental factors, which themselves lead to preterm birth. ${ }^{4}$ Further potential causes may lay in disturbance to the parent-infant relationship associated with preterm delivery ${ }^{5}$ and the effect that maternal psychological stress $^{6}$ and altered maternal perception of her child ${ }^{7}$ may also have on child development.

There have been claims that family based interventions after discharge may enhance outcome, ${ }^{89}$ with resultant calls for such interventions in the United Kingdom. ${ }^{10}{ }^{11}$ It is difficult to assess the relevance of previous studies to the UK, in view of the differing level of organisation of primary care support and the inclusion in those studies of large numbers of more mature infants.

In 1990 we embarked on a geographically based controlled study of developmental intervention after very preterm birth. Our goals were to assess the impact of introducing a home based developmental education programme to families with very preterm children, and to isolate the effects accruing from the programme itself as opposed to the social support provided by having regular home visits. We hypothesised that developmental education would improve developmental scores at 2 years and that the effect would be maximal in those at highest perinatal risk. We predicted that social and demographic factors would exert major confounding effects on the success of the intervention. This study describes the effects of intervention on the primary outcome measure-developmental scores at 2 years of age. 


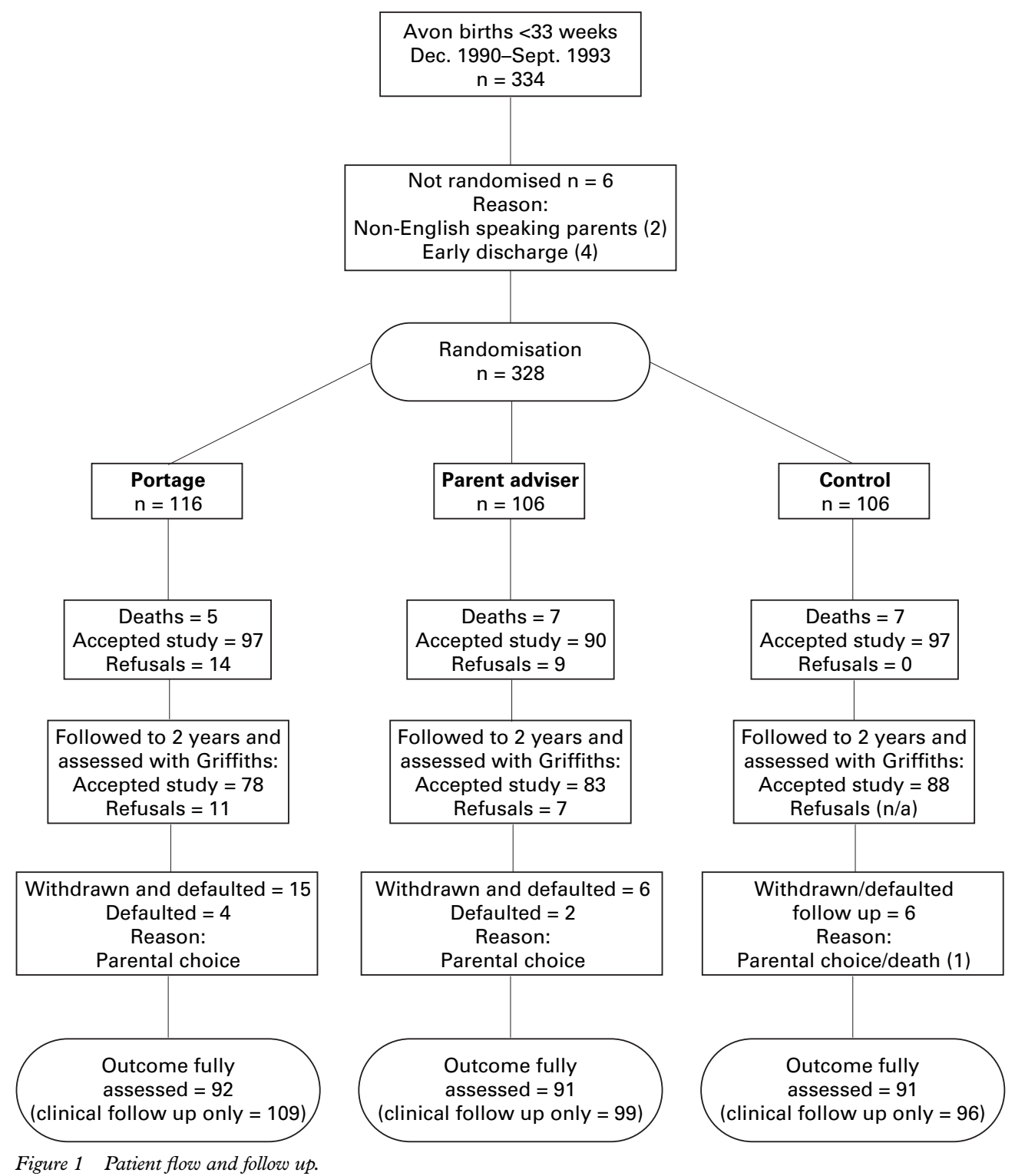

\section{Methods}

The study population comprised consecutive families with infants, born at gestational ages of 32 weeks and 6 days or less, to mothers resident in the greater Bristol area, and where English was the first language used at home. Randomisation was stratified by gestation $(<28$ weeks; >28 weeks); hospital of care (each serves different populations); families with multiple births were the subject of a separate randomisation. Randomisation was arranged in blocks of six using random number tables for each stratum. The allocation was by sealed opaque envelopes identified by stratification group and consecutively numbered, which were opened after the completion of a register between the 7th and 10th day after birth. The envelopes were prepared before the study started, by the lead author, and opened by the study nurses completing the register.

We randomised 328 consecutive infants into one of three groups: Portage, parent adviser, and preterm control (fig 1). During the recruitment period (December 1990-July
1993) two infants were excluded because English was not the first language used at home and four infants born at 32 weeks of gestation were missed because of early discharge policies. Three children born outside the study area because of antenatal transfer for delivery but subsequently returned for convalescent neonatal care were included. The remainder received full care at St Michael's or Southmead Hospitals, Bristol. Nineteen children died before discharge. The families of the 309 survivors were approached for consent after randomisation, as one goal was to evaluate the acceptability and impact of the intervention in population terms. The three preterm groups were well matched for perinatal variables (table 1). Given the variation in birthweight between groups (Kruskall Wallis one way ANOVA: $p=0.046$ ), a Z score of weight for gestation was used as a covariate in the analysis to control for any effects of growth restriction.

The mothers of 109 singleton term infants, born by vertex vaginal delivery, with no evidence of perinatal compromise, and not 
Table 1 Perinatal factors, social variables, and disability

\begin{tabular}{|c|c|c|c|}
\hline \multirow[b]{2}{*}{ Variables } & \multicolumn{2}{|l|}{ Intervention } & \multirow[b]{2}{*}{$\begin{array}{l}\text { Control preterm } \\
n=99\end{array}$} \\
\hline & Portage $(n=111)$ & $\begin{array}{l}\text { Parent adviser } \\
(n=99)\end{array}$ & \\
\hline \multicolumn{4}{|l|}{ Perinatal factors: } \\
\hline Gestational age (weeks) & $31(29-32)$ & $30(29-31)$ & $31(28-32)$ \\
\hline Birthweight $(\mathrm{g})$ & $\begin{array}{l}1560 \\
(1280-1735)\end{array}$ & $\begin{array}{l}1331 \\
(1078-1700)\end{array}$ & $\begin{array}{l}1420 \\
(1095-1700)\end{array}$ \\
\hline Males & $68(62 \%)$ & $50(50 \%)$ & $59(59 \%)$ \\
\hline Twin pregnancies $\star$ & $\begin{array}{l}24 \text { children } \\
\text { (22\% group) } \\
14 \text { families }\end{array}$ & $\begin{array}{l}20 \text { children } \\
\text { (20\% group) } \\
11 \text { families }\end{array}$ & $\begin{array}{l}14 \text { children } \\
\text { (14\% group) } \\
7 \text { families }\end{array}$ \\
\hline Number ventilated & $73(67 \%)$ & $72(72 \%)$ & $68(68 \%)$ \\
\hline Duration of ventilation (d) & $4(2-6)$ & $5(2-11)$ & $5(2-9)$ \\
\hline Oxygen therapy at 36 weeks of gestation & $14(13 \%)$ & $10(10 \%)$ & $14(14 \%)$ \\
\hline Abnormal cerebral ultrasound & 17 & 19 & 17 \\
\hline Haemorrhagic lesions & 10 & 5 & 11 \\
\hline Periventricular leucomalacia & 9 & 6 & 8 \\
\hline Days of hospital stay & $40(28-61)$ & $51(33-65)$ & $48(30-73)$ \\
\hline \multicolumn{4}{|l|}{ Social factors: $\dagger$} \\
\hline Education beyond 16 years & $45(50 \%)$ & $47(53.4 \%)$ & $55(66.3 \%)$ \\
\hline Non-manual SES & $31(34.1 \%)$ & $27(30.3 \%)$ & $40(48.8 \%)$ \\
\hline Lives with both parents & $84(91.3 \%)$ & $72(81.8 \%)$ & $72(88.9 \%)$ \\
\hline Single child & $34(37 \%)$ & $45(51.1 \%)$ & $44(53 \%)$ \\
\hline Use of car by mother & $49(56.3 \%)$ & $49(56.3 \%)$ & $55(72.4 \%)$ \\
\hline \multicolumn{4}{|l|}{ Disability at 2 years: } \\
\hline No disability & 94 & 89 & 82 \\
\hline Impaired/no disability & 4 & 3 & 4 \\
\hline Disability not severe & 2 & 2 & 5 \\
\hline Severe disability & 11 & 5 & 8 \\
\hline $\begin{array}{l}\text { Cerebral palsy (No with severe } \\
\text { disability) }\end{array}$ & $12(9)$ & $7(6)$ & $11(10)$ \\
\hline Mean (SEM) 2-year Griffiths & $70.4(7.9)$ & $59.5(9.2)$ & $68.5(9.1)$ \\
\hline Quotient for disabled children & $\mathrm{n}=10$ & $\mathrm{n}=6$ & $\mathrm{n}=10$ \\
\hline
\end{tabular}

Data expressed as median (interquartile range) or number (\%) as appropriate; tgroup totals vary slightly as not all parents answered all questions

* No higher order multiples in this population

admitted to the intensive care nurseries, were recruited immediately after birth to act as a reference population. All but eight cases were matched on eight demographic variables, with mothers recruited into the Portage group according to: maternal ethnic group, age, height, parity, support status, socioeconomic status, smoking and child's gender.

INTERVENTIONS

The two intervention groups (Portage and parent adviser) were structured to be as similar as possible in number of intervention workers, visiting frequency, and supervision by a clinical psychologist. All interventions were mediated by nurses with either nursery nurse $(n=6)$ or state enrolled nurse $(n=2)$ qualifications and experience of the hospital care of small babies. All received basic training in child protection issues and in non-directive counselling skills.

Developmental intervention: the Portage group Portage (London: NFER Nelson) is a widely available package that has been adapted for use in the UK. It has evolved from its original profile under the auspices of the National Portage Association (NPA), two members of which were involved in designing and planning the

Table 2 Visiting profile of intervention groups

\begin{tabular}{|c|c|c|c|c|}
\hline & \multicolumn{2}{|c|}{ Portage $(n=93)$} & \multicolumn{2}{|c|}{ Parental support $(n=89)$} \\
\hline & Median & $25-75 \%$ & Median & $25-75 \%$ \\
\hline \multicolumn{5}{|l|}{ Number of visits: } \\
\hline Discharge to 6 months post term & 17 & $15-20$ & 16 & $12-24$ \\
\hline $6-12$ months post term & 11 & $9-13$ & 12 & $8-15$ \\
\hline $12-18$ months post term & 8 & $5-10$ & 8 & $6-10$ \\
\hline $18-24$ months post term & 6 & $0-10$ & 6 & $0-7$ \\
\hline Length of visit (minutes) & 44 & $34-52$ & 45 & $33-54$ \\
\hline
\end{tabular}

study and in training the research nurses. Although Portage is frequently used for children with severe developmental disabilities, we used it for its original target populationchildren with developmental delay. The package has not been the subject of a randomised trial but has been evaluated in Wessex ${ }^{12}$ and South Wales. ${ }^{13}$ In practice, the introduction of Portage to the family in the first few months was felt to be weak. The research team developed a programme of activities to introduce the parent to aspects of their child's development, which facilitated the introduction of Portage earlier and which was formalised 6 months into the study. ${ }^{14}$ The detailed precision teaching, which involves a task analysis approach, was generalised for many of the children who were developing normally, within the Portage model. Throughout the course of the project, care was taken to maintain consistency of intervention. The four nurses (CI, DP, EL, JSm) received weekly structured supervision by a clinical psychologist (SD) and regular contact with the NPA.

\section{Non-developmental intervention: the parent adviser group}

The primary focus of Portage is the developmental progress of the child, although parental support is provided as part of the delivery. We considered it important to control for the support aspect of Portage, and thus developed a second intervention with parental support as the main focus, based on the parent adviser scheme. ${ }^{15}$ The training comprised a series of seminars and individual and group work, using a supportive counselling model. To isolate the effect of the developmental intervention further, the research nurses from the Portage group were also trained in this intervention. Ongoing supervision for the four parent adviser nurses (JBe, AH, JS, KF) was supplied on a weekly basis by a clinical psychologist (CM, $\mathrm{AH})$.

\section{Intervention delivery}

Both interventions began on discharge from the intensive care nurseries. Visiting was weekly for the first few months, reduced to 2-4 weekly for the next year, and then to monthly by the

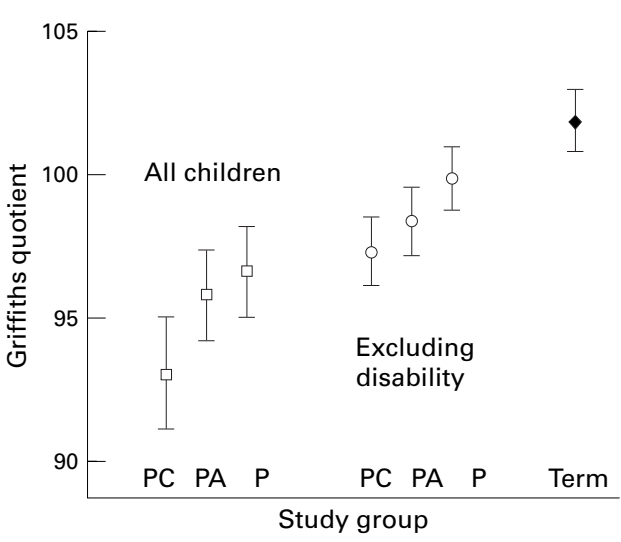

Figure 2 Mean (SEM) Griffiths scores at 2 years in the three trial groups, with and without disability, and term reference population. P: Portage; PA: parent adviser; PC: preterm control. 
Table 3 Secondary analysis of effects of disability, gender, multiple pregnancy, uptake, and practice effects on 2 year Griffiths scores

\begin{tabular}{|c|c|c|c|c|c|c|}
\hline \multirow[b]{2}{*}{ Variable } & \multicolumn{2}{|c|}{ Portage } & \multicolumn{2}{|c|}{ Parent adviser } & \multicolumn{2}{|c|}{ Preterm control } \\
\hline & $N$ & $\begin{array}{l}\text { Mean } \\
(S E M)\end{array}$ & $N$ & $\begin{array}{l}\text { Mean } \\
(S E M)\end{array}$ & $N$ & $\begin{array}{l}\text { Mean } \\
\text { (SEM) }\end{array}$ \\
\hline \multicolumn{7}{|l|}{ Disability } \\
\hline All children & 89 & $96.8(1.6)$ & 90 & $95.9(2.0)$ & 88 & $92.9(2.0)$ \\
\hline Exclude disability & 79 & $100.1(1.1)$ & 84 & $98.5(1.2)$ & 77 & $97.3(1.2)$ \\
\hline \multicolumn{7}{|l|}{ Gender } \\
\hline Males & 58 & $95.1(2.3)$ & 45 & $96.4(1.9)$ & 53 & $91.1(3.0)$ \\
\hline Females & 31 & $99.9(1.9)$ & 45 & $95.5(2.7)$ & 35 & $95.6(2.4)$ \\
\hline \multicolumn{7}{|l|}{ Multiple pregnancy } \\
\hline Singletons & 73 & $96.0(2.0)$ & 71 & $97.9(1.9)$ & 74 & $92.2(2.3)$ \\
\hline Twins & 16 & $100.2(1.2)$ & 19 & $88.6(2.8)$ & 14 & $96.6(3.4)$ \\
\hline \multicolumn{7}{|l|}{ Uptake of intervention } \\
\hline More than 10 visits & 83 & $96.8(1.7)$ & 86 & $95.5(1.7)$ & 88 & $92.9(2.0)$ \\
\hline \multicolumn{7}{|l|}{$\begin{array}{l}\text { Practice effects (excluding those } \\
\text { with disability) }\end{array}$} \\
\hline Exclude first 15 in each group & 69 & $100.6(1.1)^{\star}$ & 71 & $99.2(1.4)$ & 68 & $96.9(1.2)$ \\
\hline
\end{tabular}

${ }^{\star} \mathrm{p}<0.05$ (Portage $v s$ Controls)

time disengagement occurred at 2 years, or earlier if requested by the parent. To a limited extent the frequency of visiting was tailored to suit the family. The visiting frequency and duration of each visit was similar for each group (table 2). The research nurse endeavoured to coordinate care with each family's health visitor. Following a referral to the community disability service, the research nurse liaised with the disability team to facilitate management.

Regular outpatient visits occurred as part of the normal neonatal service. Both term and preterm children were examined by independent observers at 2 years (AE, GR, DR) who were blinded to study group. Disability and impairment were coded by one observer (NM) using standardised definitions. ${ }^{16}$

Development was assessed blind to study group at a home visit at 12 months, correcting for prematurity (JB) and again at 24 months (MR), using the Griffiths Mental Development Scales. At each visit parent(s) were interviewed using a structured format covering aspects of child care and family support. Social and demographic data were collected at discharge from the intensive care nursery and these data were reviewed at each visit; data used in this analysis related to the status of the family at birth of the index child. At all three points, self-completion questionnaires were administered, investigating maternal well being, life events, and social network.

STATISTICAL AND ETHICAL CONSIDERATIONS The study size was calculated to detect a 5-6 point difference in Griffiths scores at 2 years in subgroups comprising 35 or more children of the primary population at conventional statistical tolerances $(\alpha=0.05 ; \beta=0.80)$. Social and perinatal variables were identified as possible

Table 4 Multiple regression analysis: independent effects of factors on Griffiths quotient at 2 years (preterm children only)

\begin{tabular}{lllll}
\hline Variable & Size of effect $(B)^{*}$ & SE B & $95 \%$ CI & p Value \\
\hline Both parents at home & +5.83 & 1.88 & $(0.8$ to 9.6$)$ & .0023 \\
Non-manual SES & +6.04 & 1.28 & $(3.0$ to 9.2$)$ & .0000 \\
Maternal age (per year) & +0.33 & .13 & $(0.1$ to 0.7$)$ & .0127 \\
Number of siblings (per sibling) & -2.85 & .60 & $(-1.4$ to -4.2$)$ & .0000 \\
Use of car by mother & +3.37 & 1.32 & $(0.1$ to 6.1$)$ & .0112 \\
\hline
\end{tabular}

${ }^{\star} \mathrm{GQ}$ points confounders. Target group size was 100 children, to permit assessment of subgroups which comprised roughly $40 \%$ of each group, allowing for $10 \%$ loss to follow up. Randomisation was completed before parents were approached to facilitate identification of population effects and remove selection bias. Results were reported on an intention to treat basis unless otherwise stated.

Perinatal variables were abstracted from the clinical notes. Prospective follow up data and information from the psychometric assessments were entered on to computer and analysis was performed using SPSS for Windows (6.1). Multiple regression was performed using the SPSS linear regression option. Normally distributed data (such as GQ test scores) were compared using Student's $t$ test. Non-parametric tests were used for all other comparisons.

This study was approved by the research ethics committees of Bristol and Weston, Southmead and Frenchay health authorities.

\section{Results}

We recorded survival and disability for all preterm children, regardless of whether or not the intervention was accepted. For 20 children this was obtained from the primary health care team as their parents declined the 2 year assessment. For two children who had defaulted follow up because of family moves, confirmation of normality was achieved at 3 years. One child, whose family had moved to the Netherlands, had a home clinical assessment at 23 months ( 20 months post term). The success of ascertainment and developmental assessment is shown in fig 1, displayed according to current recommendations. ${ }^{17}$

NEUROLOGICAL OUTCOME

The neurological outcomes for 309 preterm children are summarised in table 1. One severely handicapped child died in the second year but has been included in the poor outcome group in view of his severe pre-existing disabilities. Twenty four children $(7.8 \%)$ had severe disability, nine $(2.9 \%)$ had disability not classified as severe, and 11 (3.6\%) had impairments with no or minimal disability. Thirty children $(9.7 \%)$ had cerebral palsy, 12 (3.9\%) sensorineural hearing loss, two $(0.6 \%)$ severe visual impairment (optic atrophy (1), retinopathy of prematurity (1)). Disability was evenly distributed across the three groups such that $87 \%$ of the Portage group, $93 \%$ of the parent adviser group, and $87 \%$ of the preterm controls were free of disability. GQ was not assessed for seven severely handicapped children; mean GQ for the remaining disabled children was 65.6 (range 25 to 105) (table 1). One term child developed severe spastic quadriplegia (no Griffiths assessment at parents' request), one further term child had low Griffiths scores at 2 years and has developed autistic features and learning difficulties.

\section{PRIMARY HYPOTHESIS}

The distribution of Griffiths scores across the four study groups is shown in fig 2. Mean (SEM) scores, analysed on an intention to treat 


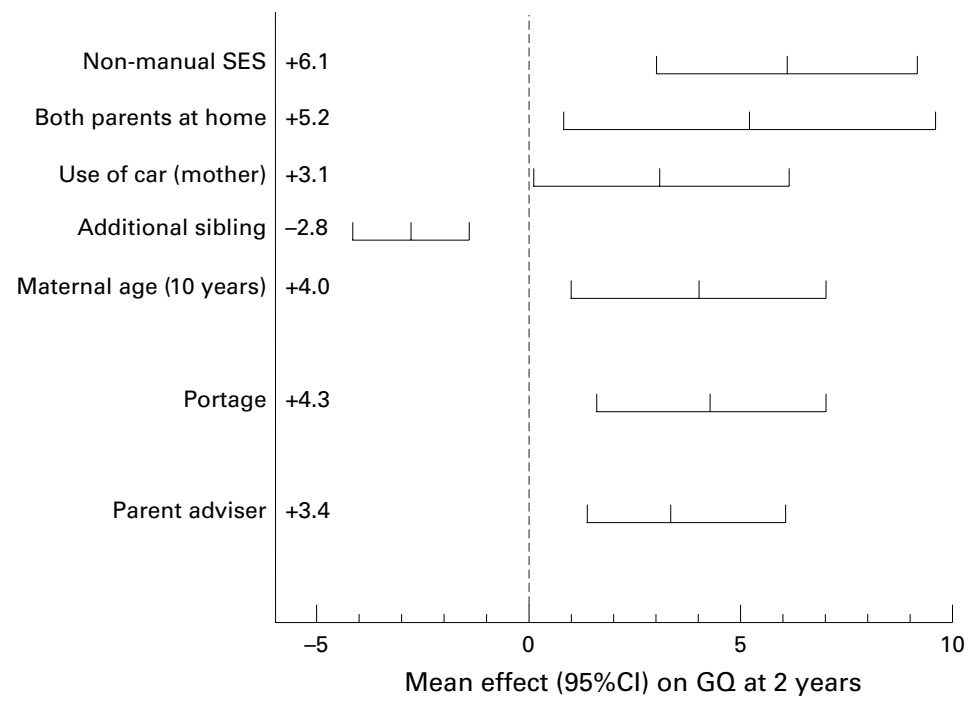

Figure 3 Effect size $(95 \%$ CI) of social variables and intervention on Griffiths scores ( $G Q$ points) at 2 years.
2.8 points ( -0.4 to 6.0 ) (fig 2 ). Whereas previously all three preterm groups had significantly lower scores compared with the term reference group, now only preterm control had lower scores (mean difference 4.7 points (1.6 to 7.8)).

EFFECT OF INTERVENTION

The uptake of intervention was similar in both groups (Portage $83.7 \%$; parent adviser $90.2 \%$; $\mathrm{p}=0.18)$. There were no differences in group GQ scores using different cutoff points for number of visits.

Despite a three month practice period, during which nurse training and working with families progressed in parallel, the research nurses probably delivered intervention more effectively as the study progressed. The Portage group also developed their service introduction during the first months. Repeating the above analyses after exclusion of the first 15 patients in each group (table 3 ) still showed no overall benefit for intervention groups (mean difference from controls: Portage: 4.5 ( -1 to 10 ); parent adviser: $5.1(-0.3$ to 10.5$)$ ), but a small advantage for Portage when children with severe disability were excluded (Portage: 3.8 (0.7 to 6.9$)$; parent adviser: 2.2 ( -1.5 to 5.8$)$ ). There was no evidence of differential effect before or after the midpoint of recruitment.

\section{SOCIAL AND DEMOGRAPHIC FACTORS}

No differential effect was shown between twins or singletons, boys or girls for demographic and social factors.

Despite randomisation, the prevalence of social factors varied between groups (table 1) and we considered that these effects might have confounded the results. More preterm control mothers had received education after 16 years of age, were in non-manual occupations and had the use of a car compared with other groups; fewer parent adviser children lived with both parents, and fewer Portage children had siblings. Using linear regression, social variables were all independently associated with GQ scores in the preterm population, explaining $33.8 \%$ of the variance in 2 year scores (table 4). Within this regression model, an improvement in scores was found with both Portage and parent adviser interventions (4.3 points 4.8 ) and between Portage and preterm control

Table 5 Results of Griffiths testing at 2 years grouped by perinatal variables

\begin{tabular}{|c|c|c|c|c|c|c|}
\hline \multirow[b]{2}{*}{ Variable } & \multicolumn{2}{|c|}{ Portage } & \multicolumn{2}{|c|}{ Parent adviser } & \multicolumn{2}{|c|}{ Preterm control } \\
\hline & $N$ & Mean (SEM) & $N$ & Mean (SEM) & $N$ & Mean (SEM) \\
\hline \multicolumn{7}{|l|}{ Birthweight } \\
\hline$\leqslant 1250 \mathrm{~g}$ & 22 & $100.5(1.6)^{\star}$ & 36 & $98.1(1.7)$ & 29 & $95.3(1.9)$ \\
\hline$>1250 \mathrm{~g}$ & 57 & $100.0(1.4)$ & 47 & $99.0(1.7)$ & 48 & $98.5(1.5)$ \\
\hline \multicolumn{7}{|l|}{ Gestation } \\
\hline$\leqslant 28$ weeks & 14 & $97.9(2.2)$ & 20 & $98.6(2.4)$ & 18 & $95.1(2.6)$ \\
\hline$>28$ weeks & 65 & $100.6(1.2)$ & 63 & $98.6(1.4)$ & 59 & $97.9(1.3)$ \\
\hline Small for dates $(<10$ th percentile $)$ & 10 & $102.9(3.6)$ & 7 & $95.2(4.1)$ & 8 & $95.8(3.1)$ \\
\hline Appropriate size for gestation & 69 & $99.7(1.1)$ & 76 & $98.9(1.3)$ & 69 & $97.4(1.3)$ \\
\hline Abnormal ultrasound & 17 & $100.4(2.3)^{\star}$ & 19 & $99.0(2.5)$ & 17 & $93.1(1.5)$ \\
\hline Normal ultrasound & 59 & $100.1(1.3)$ & 63 & $98.5(1.4)$ & 58 & $98.7(1.4)$ \\
\hline Any haemorrhage & 10 & $102.4(3.5)^{\star}$ & 5 & $94.6(3.0)$ & 11 & $93.4(1.6)$ \\
\hline Any periventricular leucomalacia & 9 & $98.0(2.8)$ & 6 & $94.8(4.1)$ & 8 & $90.8(2.2)$ \\
\hline Not ventilated & 24 & $98.1(2.0)$ & 24 & $100.2(2.4)$ & 25 & $98.5(1.9)$ \\
\hline Ventilated $\leqslant 7$ days & 36 & $103.1(1.6)$ & 35 & $98.3(2.0)$ & 32 & $97.0(1.9)$ \\
\hline Ventilated $>7$ days & 17 & $97.1(2.1)$ & 23 & $97.1(1.9)$ & 20 & $96.2(2.3)$ \\
\hline
\end{tabular}

${ }^{\star_{\mathrm{p}}<0.05}$ 


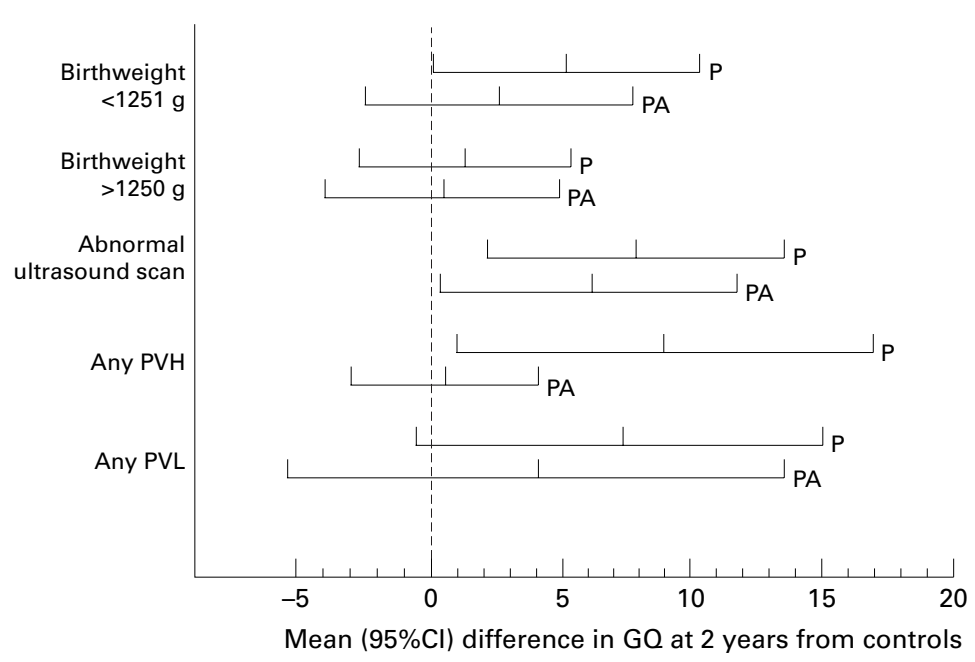

Figure 4 Mean differences in Griffiths scores (GQ points) from preterm control children for Portage $(P)$ and parent adviser (PA) groups categorised by perinatal variables.

(1.6 to 7.0 ) and 3.6 points (1.4 to 6.1 ), respectively) (fig 3).

EFFECT OF PERINATAL FACTORS

Randomisation was stratified by gestational age to match maturity and major clinical events between groups (table 1). When births below $1251 \mathrm{~g}$ were considered, Portage resulted in a 5.3 point improvement in scores compared with preterm controls (95\% CI 0.2 to 10.4 ) (table 5). This difference was not found at heavier weights. An abnormal neonatal cerebral ultrasound scan was defined as any haemorrhagic or ischaemic lesion, or as periventricular flares which persisted for more than 7 days. Considering children with abnormal scans, those who had received Portage had higher GQs than preterm controls (mean difference 7.3 points (1.6 to 13.0$)$ ). This was similar whether the lesion was haemorrhagic $(9.0 ; 1.0$ to 17.0$)$ or ischaemic $(7.3 ;-0.5$ to 15.0). No other effect of a single or combination of variables could be identified, in particular the scores of the parent adviser group did not differ from controls (fig 4). These findings were similar using raw GQs and after adjustment for social factors as described above.

\section{Discussion}

The effects of family focused interventions may influence both individual and family function. In preterm children success is conventionally evaluated by assessing the developmental or cognitive status of the child, enhancement of which was the primary motive of this study. On primary analysis we were unable to show a significant effect for developmental or parent support interventions, despite continuing those interventions over two years. This finding was not affected by secondary analysis for the potential confounding effects of disability or having used an intention to treat analysis. A minimal practice effect was shown in the Portage group, where the introduction of the intervention was modified in its application to the first few study families.

Social factors exert influence over child development in subtle ways. ${ }^{4}$ The uneven distribution of social influences across groups highlights the need to check the success of randomisation for major confounders, even with large study populations such as those described here. Because of the difficulty in knowing how best to control for this in the study design (minimisation techniques were not widely available at the onset of the study), we planned to correct for this using multivariate analysis. In this way we demonstrated a small improvement in developmental scores at 2 years in children following either intervention, Portage or parent adviser. None the less this effect remains smaller (4.3 and 3.6 GQ points for each group, respectively) than that predicted and is much smaller than 0.5 standard deviations (7.5 points), which has been suggested as a worthwhile intervention effect. ${ }^{8}$

Portage was selected as the intervention for this study for several reasons. It is widely accepted and available in the UK as part of community child health and education services, it has been adapted for British culture and is regularly updated. There is a large body of published evidence to support this, despite the fact that there have been no controlled trials of its use. In contrast to the model of delivery in clinical practice, which ceases when a child's development appears normal, we continued to focus on developmental education, because we recognised that we were attempting to improve scores over the whole range. Furthermore, as many children were developing normally and had received one year's intervention, we allowed the visits to decrease in frequency over the second year. We can speculate that continuing intensive visiting over the second year might have improved the effect, but resource constraints dictated that this was not feasible.

In biological terms there is reason to believe that developmental training, such as is encouraged by the application of Portage, may help children with clinical or subclinical neurological lesions, by optimising performance during a period of brain plasticity. ${ }^{18}$ The critical period for such intervention has not yet been identified. We found benefit from Portage in two particular risk groups-those with birthweights below $1250 \mathrm{~g}$ and those with identified lesions on cerebral ultrasound scans. In contrast to other secondary analyses on this population, the parent adviser group did not show the same effect. These results should be interpreted with caution, as the number of children with identified ultrasound lesions was small and much lower than had been predicted when the study was conceived in 1989. None the less other studies have pointed to the potential importance of ultrasound abnormalities that do not produce disability. ${ }^{19} 20 \mathrm{We}$ speculate that the increased developmental risk in such children might be ameliorated by developmental intervention.

Several similar studies of developmental intervention in low birthweight populations have been reported, but only one has sought to separate and identify the effective components of the intervention ${ }^{21}$; and none has maintained a strict population basis. Several studies have effectively targeted disadvantaged populations, 
which were also of low birthweight or preterm. $^{22}$ All large studies have recruited babies who were much heavier at birth and of more mature gestation.

The Infant Health and Development Program (IHDP) reported results of intensive interventions, used for three years in eight US cities. $^{23}$ Entry criteria were based on more mature ( $<37$ weeks of gestation), low birthweight children $(<2500 \mathrm{~g})$, further defined by lack of major neonatal neurological morbidity, parental access to telephones, and residence within a specific travelling time of the hospital. Following informed consent, only $76 \%$ of the eligible population entered the study. On first analysis, the very low birthweight group seemed not to benefit from the intervention, but further analysis controlling for confounders has demonstrated benefit. ${ }^{24}$ In this study after correction for social confounders, the size of the intervention effect of Portage on developmental scores is small, amounting to 0.34 standard deviations in term GQ scores (95\% CI 0.13-0.56), compared with the effects found at 2 years in the IHDP (no effect on motor scores, effect size: 0.46 (vocabulary); 0.49 (receptive language); 1.01 (visual motor and spatial skills)). ${ }^{24}$

We designed our trial size on the basis that an improvement of 5-6 GQ points (0.4-0.48 SD) would be detected on subgroup analysis. That the effect was smaller than predicted may be due to several factors. Firstly the population was selected on a geographical and gestational basis; families from all social groups participated, tending to minimise any effect when compared with studies targeted at families with identified needs. Secondly, this is one of the first studies of outcome after the introduction of surfactant replacement and antenatal steroids, and where an attempt was made to ensure optimal nutritional intake using early enteral feeding, preterm formula, and breast milk calorie supplements. Lucas and colleagues have demonstrated that this nutritional approach improves developmental scores at 18 months post term. ${ }^{25}$ Finally, the observed rate of ultrasound detected brain lesions was lower in this population than in previous reports of outcome, in keeping with other recent observations that such rates are falling. ${ }^{26}$ Thus these factors may independently have improved outcome for very preterm children, making it more difficult to demonstrate the effect of post discharge intervention by reducing the size of the disadvantage.

The parent adviser scheme produced a similar order of effect on child development compared with a developmentally focused intervention. This observation poses an important question about the origin of the effects found in previous studies. Are these direct effects of the structured intervention or indirect effects mediated by improving maternal confidence, wellbeing, or self esteem? We are further analysing parents' psychological health and perceptions of their children to assess this.

Non-directive support, such as that used in the parent adviser scheme but provided by lay workers, has been shown to have effects on child development for populations of Bengali families living in poor social conditions and for caucasian families with severely disabled children in the East End of London (a disadvantaged locality). ${ }^{27}{ }^{28}$ The success of social support interventions questions the need for complex and structured developmental education programmes for all groups, with implications for the type of resources needed to support early intervention, particularly when aimed at disadvantaged groups. There are also implications for the training of specialist developmental workers themselves, whose effectiveness may be enhanced by emphasising the social support aspect of their intervention.

Either intervention is expensive to implement and we suggest that it will only have a small population effect. Targeting intervention may make a service more effective. Further work is required to identify those factors associated with greatest improvement in developmental performance and to evaluate the effect of intervention on other aspects of the children's function, but we would suggest that those with birthweights below $1250 \mathrm{~g}$ and those with identified brain lesions which do not lead to disability may benefit particularly from a precision developmental educational tool rather than social support.

The importance of any intervention, however, is not simply an improvement in short term disadvantage but in the production of long term benefits for the child and family. Furthermore, the predictive value of developmental tests, such as those used here, for later cognitive or educational functioning is generally not high. ${ }^{29}{ }^{30}$ The IHDP has reported outcomes at 5 years for their multisite study ${ }^{17}$ and has observed persisting effects only for the larger and more mature infants. Other studies have shown an increasing effect of intervention, several years after completion. ${ }^{31}$ A second evaluation of this population at $4-5$ years is currently underway with a view to identifying long term effects of our two interventions.

This work was supported by a five year project grant from Action Research.

Supplementary funding was provided by Crookes Health Care, Nutricia, and Milupa (UK) Ltd. We acknowledge the nvaluable support of Professor Hilton Davis, Mrs Mollie White, and the National Portage Association, who provided training and ongoing supervision of the intervention methodology, together with numerous other colleagues who provided help and support. We particularly thank all the parents and children who have contributed greatly to the project.

1 Marlow N, Roberts BL, Cooke RWI. Outcome at 8 years for children with birthweights of $1250 \mathrm{~g}$ or less. Arch Dis Childhood 1993;68:286-90.

2 Botting N, Powls A, Marlow N, Cooke RWI. Attention deficit hyperactivity disorder and other psychiatric outcomes cit hyperactivity disorder and other psychiatric outcomes
in very low birthweight children at 12 years. $\mathcal{F}$ Psychol Psyin very low birthweight

3 Powls A, Botting N, Marlow N, Cooke R. Motor skills at 12-13 years of age in very low birthweight children. Arch Dis Child 1995;72:F62-F6.

4 Illsley R, Mitchell RG. Low birth weight: a medical psychological and social study. Chichester: John Wiley, 1984

$5 \mathrm{McFadyen}$ A. Special care babies and their developing relationships. London: Routledge. 1994.

6 Murray L, Cooper PJ, Stein A. Postnatal depression and infant development. BMF 1991;302:978-9.

7 Stern M, Hildebrant KA. Prematurity stereotyping: effects on mother-infant interaction. Child Devel 1986;57:308-15.

8 Shonkoff JP, Hauser-Cram P. Early intervention for disabled children and their families - a quantitative analysis. Pediatrics $1987 ; 80: 650-8$. 
9 Shonkoff JP, Meisels SJ. Early childhood intervention: the evolution of a concept. In: Shonkoff JP, Meisels SJ, eds. Handbook of Early Childhood Intervention

10 Davies P. Intervention. Dev Med Child Neurol 1991:33:283 Davies
84.

11 Wolke D. Supporting the development of low birthweight infants. F Child Psychol Psychiatry 1991;32:723-41.

12 Smith J, Kushlick A, Glossop C. The Wessex Portage Project: A home teaching service for families with a preschool child showing developmental delay. University of Southampton: Wessex Health Care Evaluation Unit, 1977:125.

13 Revil S, Blunden R. Home training of pre-school children with developmental delay: report of the development and evaluation of the Portage service in South Glamorgan. Cardiff: Mental Handicap in Wales Applied Research Unit, 1977.

14 Israel C, Dolby S. Parent Baby Interaction Programme. London: NFER Nelson, 1997.

15 Davis H, Rushton R. Counselling and supporting parents of children with developmental delay: a research evaluation. $\mathcal{f}$ Mental Defic Res 1991;35:89-112.

16 OHA, NPEU.Report of two working groups. Disability and Perinatal Care: Measurement of health status at two years. Oxford: Oxford Health Authority/National Perinatal Epidemiology Unit, 1994

17 Begg C, Cho M, Eastwood S, et al. Improving the quality of reporting randomised controlled trials: the CONSORT statement. $\mathscr{f A M A}$ 1996;276:637-9.

18 Anastasiouw NJ. Implications of the neurobiological model for early intervention. In: Meisels SJ, Shonkoff JP, eds. Handbook of early childhood interventions. Cambridge: Cambridge University Press, 1990:196-216.

19 De Vries LS, Regev R, Pennock JM, Wigglesworth JS, Dubowitz LMS. Ultrasound evolution and later outcome of infants with periventricular densities. Early Hum Devel

Jongmans M, Henderson S, De Vries LS, Dubowitz LMS Duration of periventricular densities in preterm infants and neurological outcome at six years. Arch Dis Child
1993;69:9-13.
21 Barrera ME, Rosenbaum PL, Cunningham CE. Early home intervention with low birthweight infants and their parents. Child Devel 1986;57:20-33.

22 Seitz V, Provence V. Caregiver-focused models of early intervention. In: Meisels SJ, Shonkoff JP, eds. Handbook of Early Childhood Intervention. Cambridge: Cambridge University Press, 1990:400-27.

23 The Infant Health and Development Program. Enhancing the outcomes of low-birth-weight, premature infants. FAMA 1990;263:3035-42.

24 McCormick MC, McCarton C, Tonascia J, Brooks-Gunn J. Early educational intervention for very low birthweight infants: results from the Infant Health and Development Program. F Pediatr 1993;123:527-33.

25 Lucas A, Morley R, Cole TJ, et al. Early diet in preterm babies and developmental status at 18 months. Lancet 1990;335:1477-81

26 Philip AGS, Allan WC, Tito AM, Wheeler LR. Intraventricular haemorrhage in preterm infants: declining incidence in the 1980s. Pediatrics 1989;84:797-801.

27 Buchan L, Clemerson J, Davis H. Working with families of children with special needs: the parent adviser Scheme. Child Care, Health and Development 1988;14:81-91.

28 Davis H, Ali Choudry P. Helping Bagladeshi families: the Parent Adviser Scheme. Mental Handicap 1987;16:48-51.

29 McCune L, Kalmanson B, Fleck MB, Glazewski B, Sillari J. An interdisciplinary model of infant assessment. In: Meisels SJ, Shonkoff JP, eds. Handbook of Early Childhood Intervention. Cambridge: Cambridge University Press, 1990:219-45.

30 Largo RH, Graf S, Kundu S, Hunziker U, Molinari L. Predicting developmental outcome at school age from infant tests of normal,at-risk and retarded infants. Dev Med Child Neurol 1990;32:30-45.

31 Achenbach TM, Howell CT, Aoki MF, Rauh VA. Nine year outcome of the Vermont program for low birthweight infants. Pediatrics 1993;91:45-55. 